This is the postprint version. For the full article:

Clarence, S., Albertus, L. and Mwambene, L. 2014. Building an evolving method and materials for teaching legal writing in large classes. Higher Education, 67(6), 839-851. DOI: 10.1007/s10734-0139707-8.

\title{
Building an evolving method and materials for teaching legal writing in large classes
}

\section{Sherran Clarence, ${ }^{1}$ Latiefa Albertus and Lea Mwambene}

\begin{abstract}
In South Africa and in other parts of the world, many professions are bemoaning the poor ability of many graduates to communicate their skills and knowledge effectively once they enter the workplace. Increasingly, pressure is placed on higher education to do more in terms of equipping future professionals with the necessary critical reading, research, thinking and writing skills the workplace demands. However, in South Africa especially, the demand for access to higher education is resulting in increased admissions, and in many lecturers standing in front of larger classes filled with students from a wide range of home and educational backgrounds with 'variable' commands of English as a medium of instruction and communication (Greenbaum and Mbali 2002). This makes the task of equipping these students with disciplinary knowledge and skills challenge. In responding to this challenge, the Law Faculty at the University of the Western Cape (UWC), in collaboration with a writing specialist, initiated a project aimed at transforming the way in which legal writing was taught at first year level. The overall aim was to start training students, from first year, to adapt their thinking and writing to the kinds of knowledge and practice required by academic study as well as the legal profession. The project was successful in achieving its modest aims, but certain challenges remain. This paper reflects critically on the development and evolution of the model for teaching legal writing in large classes. It argues that teaching legal writing in large classes requires creative and sustainable approaches so that students can become active and critical writers, readers and thinkers over time in this, or any, field.
\end{abstract}

Keywords: academic literacies; academic writing; collaboration; discourse; large class teaching; Law; legal writing.

\section{Introduction}

In 2009, the Law Faculty at the University of the Western Cape (UWC) was approached by the Centre for Higher Education (CHED) at the University of Cape Town (UCT) to participate in a research project with the aim of

\footnotetext{
${ }^{1}$ Corresponding author: sherranclarence@gmail.com
} 
improving teaching and learning in large classes. The funded project ran from January 2010 to November 2011, and was internally monitored and externally assessed.

One of the major concerns raised at UWC was that students in the undergraduate LLB degree programme lack appropriate legal and also basic writing skills, and that these are difficult to teach in large classes. The ability to write clearly, concisely and in appropriate language, form and style, regardless of the route that an LLB graduate pursues, is vital in legal practice. This need, and also the Faculty's concerns about their own students, is reflected in the LLB Curriculum Research conducted by the Council on Higher Education (CHE) in South Africa in 2010. The Law Society of South Africa (LSSA), commenting on the research, expressed concerns that 'a substantial number of law graduates are lacking in a number of essential skills such as research, computer work, literacy and numeracy' and that this has far-reaching effects in that under-equipped graduates will be less able to assist clients and so negatively affect clients' access to justice (De Vos 2010). Similar concerns about declining levels of capacity in terms of graduate 'skills' are echoed in countries other than South Africa, and higher education institutions around the world that also have to grapple with ways of equipping graduates with knowledge as well as relevant skills and capacities (Mbanjwa 2012; Paton 2008). In light of national concerns about Law graduates' proficiency in academic literacies, and wider concerns about equipping university graduates with appropriate literacies, the UWC project team decided to focus on improving first year students' legal writing skills hence the project was called the 'Large Class Writing Development Programme' (LCWDP).

The objectives of the project were modest, and centered on developing capacity: of students to write in more effective and appropriate ways; of lecturers to begin embedding teaching of legal writing into their courses; and of graduate lecturing assistants (GLAs) to be more supportive of students' writing development. To this end, first year lecturers, in collaboration with a writing specialist from the UWC Writing Centre, worked together over two years to pilot, revise and develop a working model for teaching legal writing in large classes. The overall aim was to embed legal writing and thinking skills within the coursework, and to thereby begin training students to adapt their thinking and writing to the kinds of tasks and reading they are required to do in an LLB degree, as well as in practice. The project was largely successful in achieving its aims, but certain challenges remain. The most significant of these is the sustainability of this model, and how to adapt the model to further embed teaching legal writing and thinking into undergraduate curricula in the faculty.

This paper begins with a discussion about the evolution of the LCWDP, and the theory that was drawn on in developing the working model. It will then discuss the relevant data and findings of the project linked to its objectives, and conclude with a brief discussion of the most significant challenges that need to be resolved moving forward.

\section{Rationale, background and objectives}

The project interventions were focused on first year students. There were four courses included - Introduction to Legal Studies, Law of Persons, Family Law and Customary Law - and in 2010 and 2011 student registration for the 
LLB programme was roughly 600 students. There are no venues on campus large enough to accommodate all these students in one class, therefore each course is taught in either two or three blocks, usually by two lecturers working together. This means each lecture is repeated at least twice per week. There were 24 GLAs in the faculty in 2010 and 26 in 2011, and each of these courses was assigned three GLAs, with an extra two GLAs in both years specially assigned to the project. The classes and the tutorials are large, and the lecturers and GLAs are under a great deal of pressure to ensure that students succeed in their first year of study.

In order to make the interventions in this project speak to the concerns with graduates' levels of skill in academic literacies, the project team looked at what students need to write about and how they need to write by the end of first year, as well as the foundation needed for further study at undergraduate level. Taking student assignments set in previous years, the team looked at what students were asked to write, what they were taught and what they were and were not able to do with their written tasks. The pass rates in all four modules were lower than desired and poor writing on the part of low achieving students was certainly part of the reason for this. In addition to the lowered pass rates, the lecturers involved felt that many students were not coping adequately with writing in further years based on their first year experiences. Apart from answering formal assignment tasks as part of their coursework, tests and exams, students do not have many opportunities to practice writing in this new legal discourse, and thus many struggle to meet the standards set by the Faculty.

The most significant concern was that many students were not showing sufficient evidence of the ability to read a set of facts analytically in the context of the governing legal framework and identify the key issue that required a response. If the issue is incorrectly or insufficiently identified, the rest of the written answer tends to be incorrect, misguided or incomplete. Leading on from this, many students struggled to identify and apply the relevant legal principles or rules (drawn from statutes and case law) and provide a succinct written statement of these. This problem has also been noted by professional bodies like the LSSA when commenting on the skills that graduates lack in correctly applying the relevant legal principles to the pertinent facts using references to relevant cases and statutes to craft an argument to support the final conclusion (see De Vos 2010), and understanding how to reach and write a logical conclusion based on the argument developed, showing a clear sequence of logic and thinking (Jansen 2012). Thus, the ability of many students to construct and communicate coherent arguments starting from a clearly identified issue was a concern at the outset. Additionally, lecturers were adamant that students needed to have the ability to use correct grammar and spelling, as well as the appropriate tone and style in their answers. Finally, they wanted to equip the GLAs to take more of an active role in supporting students through tutorials and feedback.

The following sections will detail the theoretical underpinnings of the model and teaching approach, and will outline the methods used in developing the model.

\section{Towards an approach to teaching legal writing}

The project was broadly underpinned by an academic literacies approach to teaching writing in the discipline of Law. Briefly, this way of thinking about academic writing holds that it is not a set of discrete skills that can be 
taught and learnt outside of the discipline or in isolation from the substantive knowledge of the discipline. Academic writing is a social and socialised activity that someone does for someone else (Lillis 2001) in that there is a writer and an audience and communication between the two. The disciplinary culture one is working in shapes or informs the style and forms of writing to greater and lesser extents, and disciplinary discourses and conventions must be accounted for when writing. The disciplines we enter in higher education also function as 'discourse communities' (Candlin et al 2002: 310) in very different ways to secondary schools, and the transition needs to be taken into account when thinking about what and how students need to read, think and write. 'Discourse communities possess their own genres, specific lexis, and even analytical paradigms' (Candlin et al 2002: 310). But the discourse referred to here also involves social behaviour as a 'means of maintaining and extending the group's knowledge and of initiating new members into the group' (Swales 1990: 21). This is important to grasp, because it is necessary to acknowledge that when we talk about legal writing, we are referring to much more than simply mastering legal English, or writing in certain formats. We are referring to training future lawyers to read, think and write in ways that are valued and recognised by their discourse community, and this is a significant undertaking for lecturers and teachers in law schools and faculties. In learning to approach the study of law in ways that are recognised and valued, law students slowly become the people who hold and will uphold certain values, and take them into their chosen professions. Thus, the design of the project materials and methods was underpinned by an understanding that, while some of the challenges students experience in acquiring relevant academic literacies stem from their under preparedness for university study (see Scott, Yeld and Hendry 2007; Boughey 2002; Leibowitz 2004), many of the issues involve students struggling to understand and use particular conventions of legal academic writing, and recognise the ways of thinking and writing that are valued by the discipline (Lillis 2001; Lillis \& Turner 2001).

Learning to write in the study of law is inextricably tied up with learning the legal discourse valued and invested in by the legal community one is trying to join (Candlin et al 2002). There are approaches to teaching students to write effectively in Law programmes that focus on getting the 'language' right, but 'Legal English' (Greenbaum and Mbali 2002) is only one element of legal discourse that law students need to master in order to become proficient legal professionals. Learning legal discourse is about learning to read new kinds of materials, thinking about them in new and different ways, and writing in highly conventionalised forms within fairly stable and consistent genres, like legal briefs, memoranda and case summaries (see Candlin et al 2002). There are specific logics and forms that need to be followed when applying legal knowledge, and these shape the way that language is used in the discourse. Thus, learning the legal discourse and mastering it is a challenge for students who have English as a mother tongue as well as for students who are less familiar with using the language (Greenbaum and Mbali 2002). Greenbaum and Mbali argue that

[b]y appreciating that law students are learning to write within a highly conventionalised discourse, in which arguments are constructed according to certain unwritten rules or conventions and that a mastery of an entire new technical vocabulary is required, law teachers can avoid the tendency to categorise students [who struggle] as in need of remedial assistance (2002: 233). 
The team realised that students needed to be taught the language of the law as well as the discourse (ways of thinking, reading and writing) simultaneously (Candlin et al 2002; Greenbaum and Mbali 2002; Simon 1992). The teaching approach was thus designed to develop a workable method of teaching students to write more effective legal opinions, not as a stand-alone skill but as an embedded practice integral to being a successful legal professional (see Simon 1992).

\section{Process of developing the writing workshops}

The main focus for the team was teaching writing in large classes in interactive and viable ways. To this end, a series of writing workshops were designed and conducted during lecture periods in the first and second semesters in 2010 and 2011. The courses in which the workshops were facilitated dedicated ten percent of students' coursework marks towards the project. In order for students to obtain these marks they were required to attend the workshops and complete written tasks before the workshops ended. The aim was to have three workshops per course over the year in each of the two years of the project, but for reasons that will be discussed later on this was not possible in all courses, and the plans changed slightly from 2010 to 2011 (see Figure 1).

Figure 1: Large-class writing workshop schedule 2010-2011

\begin{tabular}{|c|c|c|}
\hline & 2010 & 2011 \\
\hline \multirow[t]{2}{*}{ Semester one } & Law of Persons ( 3 workshops) & Law of Persons (2 workshops) \\
\hline & $\begin{array}{l}\begin{array}{l}\text { Introduction to Legal Studies (2 } \\
\text { workshops) }\end{array} \\
\end{array}$ & $\begin{array}{llll}\begin{array}{l}\text { Introduction to Legal Studies } \\
\text { workshops) }\end{array} & & \\
\end{array}$ \\
\hline \multirow[t]{2}{*}{ Semester two } & Customary Law (2 workshops) & Customary Law (2 workshops) \\
\hline & Family Law (2 workshops) & $\begin{array}{l}\text { Family Law (0 workshops) } \\
\text { (Administrative challenges excluded } \\
\text { this course only from the workshops). }\end{array}$ \\
\hline
\end{tabular}

These workshops were designed by the writing specialist in collaboration with the lecturers teaching in the various courses. Although the writing specialist facilitated the workshops, the lecturers were present and contributed to the class discussion about the writing task, particularly regarding the 'substantive' law involved. The writing tasks used for the workshops were 'factual scenarios', also referred to in the literature as 'problem-solving' tasks or essays (Candlin et al 2002; Simon 1992) and required students to construct an evidenced legal opinion for a fictional client. These mimic a situation in which law students need to construct a legal opinion as if for a client, which is useful preparation for legal practice and also connects the theory with its practical application and deepens understanding of the law. The lecturers drafted the questions and prepared guidelines for the writing specialist as to the legal principles and case law involved and possible ways in which students could answer the task. The writing specialist then adapted the question into an exercise that would guide the large class discussion, as well as a marking rubric for the GLAs to assist them in giving students feedback and a mark. The lecturers commented on the rubric and suggested changes where needed, thus the material design process was both collaborative and creative. 
As part of the aim to develop a teaching method and materials that could be embedded throughout the first year curriculum and eventually in the curricula of further years of study, it was essential to make explicit the ways in which students needed to respond to the questions using the substantive knowledge they had learned in classes and tutorials. Problem-solving exercises, or factual scenarios, are a good way to teach 'substantive law' with the 'analytical and organizational skills necessary for writing' about it (Simon 1992). Through this collaborative process of designing and reflecting on the workshops, the lecturers' and GLAs' own capacity for teaching legal writing grew in practical ways, and it encouraged them to be more explicit with students. In most cases this meant changes like taking the time to explain parts of the writing process more clearly rather than assuming students understood them, or thinking more carefully about how they wrote task questions, or discussed students' writing with them either in classes or in consultations. This is ongoing, and further collaboration is needed here to extend the process of thinking about how to teach legal writing in lectures and tutorials. However, this early process has been useful in showing up potentials and also possible obstacles to achieving the goal of growing the capacity of the Faculty to take this model forward.

The team was clear from the outset that the process was an evolving one, which made it possible to reflect continuously and make necessary changes as the project progressed. The team was unsure as to how the large class sizes - approximately 200 students in each workshop - would affect the students' ability to write in class as well as the quality and depth of the discussions. However, because of the large classes at first year level, it was important for the team to set up the writing exercises as class exercises in order to develop a workable method for bringing writing more overtly into the curriculum. Embedding regular writing exercises into curricula and lectures was necessary as the aim was not to remediate students' 'bad' writing but rather to develop all students' ability to become familiar with the conventions of writing in the legal discourse.

\section{The writing workshops}

The first part of each workshop focused on a thinking process, using a legal organisational and analytical method, and applying this to the scenario at hand. The legal method used in the workshops to guide students thinking and writing processes was the 'IRAC' method. The IRAC method is a very useful analytical and organisational tool for legal writing, and although there are variations and other tools that law teachers use, IRAC is fairly standard and has great value in teaching students to respond to various legal genres like problem-solving or factual scenario questions, legal briefs and legal memoranda (Candlin et al 2002), especially in their first year of legal studies. The method, briefly, requires students to identify the issue(s) that needs to be explored; state the applicable rule(s); apply the legal rule(s) to the facts of the case; and state the logical conclusion (Candlin et al 2002).

In a factual scenario or theory question everything proceeds from an accurate analytical reading of the facts of the case. Together with the students, the facilitator read through the scenario, on a large screen on PowerPoint in 2010 and on a Document Camera (digital overhead projector) in 2011, and asked students to call out all the relevant facts they could identify. The lecturer also contributed if there was confusion on the part of the students or if they missed 
important information. Moving from the facts, the students were then asked to identify the issue or issues, and this was restated by the facilitator to clarify. Students were encouraged to take notes as the discussion progressed. Once the issue was clear, the legal principles were identified and debated by the students, and the facilitator took notes and restated and summarised the applicable principles, verbally linking them back to the issue to indicate the development of the structure in the argument. Following this, the facilitator led a discussion of the application of the principles to the case, and here the lecturers often contributed by clarifying misunderstandings or guiding the discussion. Again, these were summarised by the facilitator, linked back to the legal principles and issues, and then led forward into the conclusion, which was a clear response to the issue identified. The discussions were not fully participatory, as the classes were large and time was limited - roughly 200 students per one-hour workshop - and the number of students who called out answers was relatively small. But as the year progressed, in both 2010 and 2011, and students became more familiar with the format as well as the facilitator prompting, questioning and even feigning ignorance to encourage discussion, the discussions became somewhat more interactive.

The second part of the workshops provided students with an opportunity to write their responses. These were completed in class, and each workshop was an hour long. The workshops thus comprised 25-30 minutes for discussion and 30 minutes for writing. The time limits meant that the tasks required short answers, and this focus on brevity, while a practical consideration, is also a feature of writing in the legal discourse where students are required to stick to the facts, write only as much as is required by the question posed and write in concise, clear prose (Candlin et al 2002; Greenbaum and Mbali 2002). The students were encouraged to assist one another if they needed help during the writing part of the workshop, as these were not tests, and the lecturers, GLAs and facilitator moved around the room, stopping to assist and answer questions if students raised their hands. There was a strict requirement to complete the task in the workshop and not after, as this was a project looking at the possibility of teaching students writing during large classes with assistance from lecturers as well as their peers. A relatively small number of students compared to the class size in each year complained about this, but the discussion shaped the structure of the answer as well as revised the content to prepare students for the written task quite explicitly. There were very few students over the two years who were unable to complete the written tasks in the workshops. If they did not finish, they were unable to receive a mark, as it was unfair for them to receive a mark for a task done in more hours when the majority only had half an hour during the lecture.

The assessment of the written tasks was completed by two GLAs, both LLM students, who worked with the project team. In order for the GLAs to mark the written answers and give feedback, a clear rubric was devised by the writing specialist and lecturers. The rubric was designed to provide the GLAs as well as students with criteria for the written responses, and focused on the structure of the answers using the four areas focused on in the IRAC structure, and the use of appropriate grammar, spelling and style. The rubrics aimed to teach students how to structure and form their writing, and give GLAs clear and standardised ways of assigning marks and giving feedback, allowing students to identify their strengths and weaknesses. The rubrics were given only to the GLAs as guidance in 2010, 
but not to the students as printing costs were prohibitive for such a large class. The GLAs thus had to hand-write constructive comments on over 600 written responses, and the team realised fairly quickly in the first semester that this was unsustainable. The two project GLAs were overtaxed, and as a result could not hand back the marked work with feedback ahead of the next writing workshop. The feedback was also fairly poor as the GLAs were overwhelmed. This undermined the developmental nature of the writing process approach used in the workshops, and made the tasks seem more like tests, rather than parts of an ongoing writing process.

Figure 2: A sample rubric from 2011 - Customary Law Task 2

\begin{tabular}{|c|c|c|}
\hline $\begin{array}{l}\text { You have clearly identified the } \\
\text { issue } \\
3 / 3\end{array}$ & $\begin{array}{l}\text { You have partially identified the } \\
\text { issue } \\
2 / 3\end{array}$ & $\begin{array}{l}\text { The issue is not clearly identified } \\
0-1 / 3\end{array}$ \\
\hline $\begin{array}{l}\text { You have identified the legal } \\
\text { principles involved fully and } \\
\text { clearly } \\
6-7 / 7\end{array}$ & $\begin{array}{l}\text { You have partially identified the } \\
\text { legal principles involved } \\
4-5 / 7\end{array}$ & $\begin{array}{l}\text { You have not clearly identified the } \\
\text { legal principles/misidentified the legal } \\
\text { principles } \\
0-3 / 7\end{array}$ \\
\hline $\begin{array}{l}\text { You have accurately and fully } \\
\text { applied the case law to the } \\
\text { factual scenario and reached a } \\
\text { relevant conclusion } \\
8-10 / 10\end{array}$ & $\begin{array}{l}\text { You have partially applied the } \\
\text { case law, meaning you have only } \\
\text { partially related the relevant facts } \\
\text { of that case, and so have not fully } \\
\text { linked all the points to Mrs Y's } \\
\text { case as you should have. Your } \\
\text { conclusion is not complete, as a } \\
\text { result. } \\
5-7 / 10\end{array}$ & $\begin{array}{l}\text { You have not accurately or fully } \\
\text { applied the case law to the } \\
\text { scenario/you have left out a great deal } \\
\text { of important information/as a result } \\
\text { there isn't a logical or justified } \\
\text { conclusion } \\
0-4 / 10\end{array}$ \\
\hline $\begin{array}{l}\text { Clear overall structure }- \text { answer } \\
\text { reads well and makes sense } \\
\text { overall. Good use of cohesive } \\
\text { devices like logical connectors } \\
\text { and linked sentences; clear focus } \\
\text { on question at hand and good } \\
\text { knowledge of the topic. } \\
3 / 3\end{array}$ & $\begin{array}{l}\text { Mostly clear structure - there are } \\
\text { some places where meaning is } \\
\text { not clear and logic has broken } \\
\text { down - perhaps because of gaps } \\
\text { in your knowledge about the } \\
\text { topic or inconsistent focus on the } \\
\text { question at hand. } \\
2 / 3\end{array}$ & $\begin{array}{l}\text { The overall structure is not very clear } \\
\text { and as a result the answer is difficult to } \\
\text { understand fully - perhaps there is a } \\
\text { lack of knowledge about the topic, or } \\
\text { you have not focused enough on the } \\
\text { question and the logical methods you } \\
\text { have for answering it. } \\
0-1 / 3\end{array}$ \\
\hline $\begin{array}{l}\text { Very sound spelling and } \\
\text { grammar usage. } \\
2 / 2\end{array}$ & $\begin{array}{l}\text { Adequate spelling and grammar, } \\
\text { although there are some errors. } \\
1 / 2\end{array}$ & $\begin{array}{l}\text { Weak overall spelling and grammar - } \\
\text { lots of errors that need to be corrected. } \\
0 / 2\end{array}$ \\
\hline
\end{tabular}

In 2010 the response was to reduce the number of workshops from 3 per course to 2, and give the GLAs additional training on giving constructive feedback to students. In 2011, along with the workshop tasks, rubrics were posted on e-teaching and students were required to print and attach them to the written tasks which were handed in at the end of the workshops. This was a better solution as students saw the assessment criteria with the task ahead of the workshop. The GLAs were also able to use the rubric to give feedback, although this was fairly basic, which made their marking load lighter and students could get their work back between workshops, and use the comments to work on improving their writing. 


\section{Findings and discussion}

A great deal of data was collected and analysed in 2010 and 2011, but this paper will only draw on the data related to the effectiveness of the new teaching method as per the paper's focus.

A necessary part of analysing the effectiveness of this new model for teaching writing was determining whether students' writing actually improved over the course of the year. 100 students were selected as a sample group, ranging from 'at risk' students identified as having poor writing skills to relatively competent writers. Their written work from the writing workshops was collected, copied and analysed using each point in the IRAC structure discussed in the previous section as a category against which to assess the work using the weighting assigned in the rubric to note the importance of each area (see Figure 2). A random selection of 15 sets of workshop tasks for 15 out of the 100 students was analysed for their improved ability in each of the areas considered, as well as overall improvement in the structuring and organisation of writing. Improvements were registered in higher marks over time for most of the group, but more importantly, in the students' inclusion of all aspects of the IRAC method, and using the content to discuss the scenarios in more concise, accurate and well-structured ways. The results of this analysis indicate a positive trend for the larger group of 100 students in the sample group, which is $1 / 6$ of the full class. This data, alone, would not represent valid findings. Thus these results are considered together with student feedback gathered in focus groups with 2010 and 2011 students, and survey data from both years, as well as comments from GLAs and academic lecturers indicating the contribution the model made to improving students' legal writing.

In terms of the students' writing, the results were very encouraging in spite of the small sample. Due to the qualitative nature of the analysis, the measurement of improvement is not exact, but rather approximate. However, the results we do have provide a reasonably accurate reading of the students' improvements taken together with their own self-assessment in the survey data and the comments from students, lecturers and GLAs. Approximately $70 \%$ of the 15 students showed an improvement in their analytical reading of the facts and their ability to articulate the issue(s) identified between the first and last assignments. Approximately $60 \%$ showed an improvement in being able to identify and articulate the applicable rule(s) and legal principles. $60 \%$ of these students improved in their application of the law to the facts, which we would have liked to have been higher, but this is one of the biggest areas of struggle for students based on other assessments and years of teaching experience. Between $65 \%$ and $70 \%$ exhibited consecutive textual improvements in the construction and presentation of logical and coherent legal arguments that reached substantiated conclusions. Finally, just over half of the students analysed exhibited improvements in the basic spelling, grammar and stylistic skills. This final result was interesting, because grammar was not taught explicitly in the workshops, but students were regularly reminded to be mindful of these conventions. These results indicate, in spite of the small sample in relation to the whole group, that the methodical and overt manner of teaching the thinking and related writing process required by the IRAC method raised students' awareness of disciplinary conventions, and afforded them constructive opportunities in class to practice thinking and writing in these new ways, although there is clearly still room for improvement. 
This textual analysis is combined with feedback from students, and also from lecturers and GLAs about students' writing development. $45 \%$ of the students surveyed about the writing workshops believed that their writing had improved as a result of coming to the workshops, while $45 \%$ were unsure and only $10 \%$ said it had not improved. Students who participated in focus groups commented that the workshops helped them understand more clearly how to approach these kinds of questions, how to structure their work, and what is required of them. The comments below illustrate some of the students' views:

"The assignment exercises helped us get ready and tackle the exams. I know the way I was writing is different then and now; now I can find and make the connections in my writing."

"Without the workshop we could not structure answers in the same way we have to come to structure them."

"Because the workshops were linked to the specific courses, we had a very clear idea, thanks to the workshops, of what were the expected standards and requirements of the course, in terms of the written work requirements. The workshops gave us rules and guides on what to say and how to say it. We better understood what the lecturers want."

What is encouraging in these comments is the link between what students are improving in (structure, connections, how to say what they are saying) and the aims of the project to focus on how students are thinking and processing information before they write it.

GLAs and lecturers, too, were pleased on the whole with the way in which students were planning and organising their answers more effectively. For example, a lecturer commented in 2010 that "students generally have a better grasp of how to approach questions and produce better structured answers than before". One GLA, talking about the students in 2011, commented that she had "definitely seen a constant improvement in the writing ... They use better planning and construction and their ability and insights have improved." Taken with students' feedback and the improvements recorded in the analysis of the small sample of students' writing, it seems that the project achieved, albeit in a modest way, the aim of improving many students' ability to change their thinking and writing to meet the requirements of the study of law, although we do acknowledge that there is still much room for improvement.

A further aim was to create a model that could be taken up and adapted by lecturers in other years of study. Comments by both lecturers and students indicate that there is a realisation on both sides that the use of this kind of embedded teaching of legal writing is necessary in all years of study. Second year students (interviewed in 2011) who attended the workshops in 2010 commented that "the development of our writing skills is a process which takes place over the years, in every year. It can't be done in one year. This is especially so for legal writing. Language in this field is a big thing; to develop legal writing skills is challenging. We need support to do this to the end of $4^{\text {th }}$ 
year". Along the same lines, one of the lecturers teaching on a course that was included in the project commented that

If we look at what we want, in terms of skills, of our $4^{\text {th }}$ year students; what we want of our law graduates... The most important thing we need to focus on in the 4 years is the reading, critical analysis and writing skills. To do this we need to make sure that in all four years we are building these skills in appropriate ways - ways which will differ for students in first year compared to students in their $4^{\text {th }}$ year.

These comments echo others, not able to be included here, from students and lecturers involved in the project and indicate that this evolving model has begun to create an awareness that academic literacy development goes beyond simply correcting 'bad' writing or encouraging the use of 'good English'. Instead, it needs to happen in each year of study because it is about the ways in which substantive and procedural knowledge are brought together, and about the disciplinary discourse (Simon 1992). One of the lecturers who teaches in first and second year saw improvements in her students' analytical, written and application abilities as a result of attending the workshops and began to use the model, adapted in her own tutorials and lectures, in 2011 and continued into 2012. Several lecturers made their tutorials more writing intensive in 2012 without the assistance of a writing specialist, and two thus far have reported an improvement in students' writing as a result of this additional time for practice and feedback.

Thus, the project has started achieving its aim of embedding teaching of legal writing in law courses, although there is still a way to go in terms of teaching writing in the larger classes as part of the curriculum. Much of the writing is focused in tutorials under the tutelage of GLAs. This is a possible limitation in terms of replicating this model, as the idea is for lecturers to embed this model in their teaching. Not all writing tasks need to be assessed, and students do not need to hand in a task in every workshop. If a lecturer wants to build writing into a curriculum adapting this model, the assessment can be adapted according to the resources that are available, and other forms of assessment can be used, for example, peer assessment. There are many ways in which to adapt this model in order to replicate it, and it is designed to evolve and change over time.

\section{Conclusion}

Studies focused on large class teaching highlight different methods of increasing student engagement and participation, including the use of clickers (Trees and Jackson 2007) and various interactive discussion methods, like using problem-solving techniques and 'on the spot' questions and quizzes (Allen and Tanner 2005). There is not much focus on teaching students how to write, and this paper has attempted to make a contribution to studies on large class teaching that focus on getting students talking, thinking about, and doing writing in large classes rather than only in smaller tutorials and solo spaces. This model was focused on improving student writing within a specific set of variables, increasing capacity in terms of giving feedback and guidance, and encouraging a shift in the faculty in terms of lecturers reimagining their role as teachers of both substantive and procedural knowledge. In spite of the modest achievements, there are ongoing concerns. 
The biggest concern is the sustainability of the teaching model and consistency in the models of these tutorials. While several lecturers in first and second year have created tutorial tasks that give students opportunities to practice legal writing more often, there is no evidence yet of take-up of the model in lectures, where lecturers do what the writing specialist did: teach students not only what to write but how to write about it quite explicitly. Some of the tutorials thus far have been designed to allow time for discussion as well as writing, but others only make time for writing, presenting the tasks as 'tests' rather than as developmental exercises. While these writing intensive tutorials are a big step forward, the role that lecturers play in this approach to creating more writing-focused curricula is crucial. Lecturers are knowledgeable insiders who therefore need to make opportunities in class to build writing into the curriculum, rather than keeping it within the bounds of workshops with writing specialists or tutorials. Lecturers often feel unsure of their ability to move from teaching just the 'content' to teaching 'skills' as well, but this shift can be encouraged through workshops for lecturers on how to create their own writing workshops that blend the content with the writing and thinking 'skills' that students need to master. Greater effort will need to be made to include more lecturers in these workshops, and focus on developing their capacity to make changes to the way they see writing in the curriculum, and the way they teach their students to do it. This is a significant and ongoing challenge that speaks directly to the sustainability of this model.

Large classes are, for better or worse, a reality in South Africa's tertiary institutions, and lecturers are increasingly going to be relied on to teach students more of the reading, writing, thinking and research skills that the workplace demands. These 'skills' are not stand-alone things that students can or should be learning outside of the disciplines; rather, as this paper has shown, academic literacies are also knowledge practices. We write, think, read and research in different ways according to the conventions of the disciplines in which we work. Thus, it is crucial that all academic lecturers begin to embrace the teaching of academic literacies as part of teaching the knowledge - both substantive and procedural - of their disciplines. This process is challenging and time-consuming, but with the assistance of those in the university, like writing specialists or colleagues who have knowledge and experience in these areas of pedagogy, it can be accomplished. We hope that we have shown that it is possible in large classes to do this, and to make this enjoyable, stimulating, and creative for lecturers and students alike.

\section{References}

Allen, D., \& Tanner, K. (2005). Infusing Active Learning into the Large-enrollment Biology Class: Seven Strategies, from the Simple to the Complex. Cell Biology Education, 4 (2005), 262-268.

Boughey, C. (2002). 'Naming' Students' Problems: an analysis of language-related discourses at a South African university. Teaching in Higher Education, 7(3), 295-307.

Candlin, C.N., Bhatia, V.K., \& Jensen, C.H. (2002). Developing legal writing materials for English second language learners: problems and perspectives. English for Specific Purposes, 21 (2002), 299-320. 
De Vos, P. (2010). Law Society bemoans "lack of basic skills" of law graduates. Constitutionally Speaking. http:/constitutionallyspeaking.co.za/law-society-bemoans-lack-of-basic-skills-of-law-graduates/. Accessed 28 October 2012.

Greenbaum, L., \& Mbali, C. (2002). An analysis of language problems identified in writing by low achieving firstyear students, with some suggestions for remediation. South African Linguistics and Applied Language Studies, 20, 233-244.

Jansen, L. (2012). Lack of skill in law graduates, says judge. IOL News. http://www.iol.co.za/news/crimecourts/lack-of-skill-in-law-graduates-says-judge-1.1351806\#.UKn5DYdRfwY. Accessed 19 November 2012.

Leibowitz, B. (2004). Becoming Academically Literate in South Africa: Lessons from Student Accounts for Policymakers and Educators. Language and Education, 18(1), 35-52.

Lillis, T. (2001). Student Writing. Access, Regulation, Desire. London and New York: Routledge.

Lillis, T.M., \& Turner, J. 2001. Student writing in Higher Education: contemporary confusion, traditional concerns. Teaching in Higher Education, 6(1), 57-68.

Mbanjwa, X. (2012). Young, jobless and desperate - Degrees with no guarantees. City Press. http://www.citypress.co.za/SouthAfrica/News/Young-jobless-and-desperate-Degrees-with-no-guarantees20120616. Accessed 19 November 2012.

Paton, G. (2008). More graduates lack skills to win jobs. The Telegraph. http://www.telegraph.co.uk/news/1577111/More-graduates-lack-skills-to-win-jobs.html. Accessed 19 November 2012.

Scott, I., Yeld, N., \& Hendry, J. (2007). A Case for Improving Teaching and Learning in South African Higher Education, HE Monitor, No. 6, October. Council on Higher Education, Pretoria.

Simon, M.S. (1992). Teaching writing through substance: the integration of legal writing with all deliberate speed. Pace Law faculty Publications, Paper 220. http://digitalcommons.pace.edu/lawfaculty/220. Accessed 28 May 2012.

Swales, J. (1990). Genre analysis: English in academic and research settings. Cambridge: Cambridge University Press.

Trees, A., \& Jackson, M.H. (2007). The learning environment in clicker classrooms: student processes of learning and involvement in large university-level courses using student response systems. Learning, Media and Technology, 32(1), 21-40. 